\title{
Bossa Nova como régua e compasso: apontamentos sobre a crítica musical no Brasil
}

\section{Marildo José Nercolini}

\section{Resumo:}

Este ensaio pretende refletir sobre a crítica musical massiva no Brasil, atendo-se ao período compreendido entre o final dos anos 50 e a década de 60. A hipótese aqui levantada é que os parâmetros em termos de valores estético-musicais aí construídos tornaram-se hegemônicos nos anos posteriores, tendo a Bossa Nova e, sobretudo João Gilberto, como marcos desse processo. Para isso, inicialmente se faz uma reflexão em torno da questão da crítica em termos gerais para posteriormente se fixar na análise do período proposto e da hipótese apresentada.

\section{Palavras Chave:}

Crítica, crítica musical brasileira, Bossa Nova.

\begin{abstract}
:
The present essay ponders about the criticism over massive music in Brasil, focusing on the period between the late 50's and the 60's. The hypothesis we raise is that the parameters build in such criticism in terms of aesthetic-musical values have become hegemonic in the course of the subsequent years, having the Bossa Nova and especially João Gilberto stand out in the process. To that intent we have first theorized on the matter of criticism in general, concentrating later on the analysis of the indicated period and the presented hypothesis.
\end{abstract}

\section{Keywords:}

Criticism, Brazilian music criticism, Bossa Nova.

\section{A crítica e os críticos}

A intenção desse ensaio concentra-se na análise da crítica musical massiva no Brasil, com ênfase no período compreendido entre o final dos anos 50 e a década de 60, por supor que é nesse período que vão ser construídos os critérios de avaliação estéticos hegemônicos nos anos posteriores, centrados no legado da Bossa Nova.

Um dos pressupostos teóricos desse ensaio provém das reflexões propostas por Raymond Williams (1979, 2000), sobretudo quando propõe uma análise da cultura em termos dinâmicos, como um jogo de forças, um campo de luta em torno do significar social, em que nada está dado de antemão, mas sim é processo em constante transformação, de acordo com a correlação de forças dadas pelos sujeitos sociais no contexto em que vivem. As noções seminais de Williams sobre o "hegemônico", o "residual" e o "emergente" são fundamentais para se entender o percurso que esse ensaio quer traçar.

Em síntese, Williams (1979) nos afirma que por mais hegemônica que determinada visão de mundo (ou modo de vida), em termos gerais e mesmo pensando em áreas mais específicas, possa ser em determinado contexto cultural, ela nunca consegue abarcar a totalidade. Permanecem brechas advindas, por um lado, 
de elementos "residuais" de posições anteriormente hegemônicas ou pelo menos posições que não são contempladas pela visão então predominante, e que respondem a anseios e necessidades ainda presentes; e por outro lado, elementos "emergentes", novos anseios e necessidades provenientes de parcelas sociais insatisfeitas com o atual quadro de forças, que se sentem representadas e que se propõem a fazer valer seu papel como agentes/sujeitos no jogo de forças dentro do processo de atribuição e circulação de significados sociais; uma proposta que vai se construindo como "emergente", a questionar e a propor alternativas, confrontando-se com o hegemônico. Nesse campo de lutas, entre confrontos e negociações, a cultura se faz e refaz, processual e dinamicamente. É dentro dessa perspectiva que trabalhamos aqui.

Em relação à reflexão sobre a crítica e sua função, comungo com o pensamento de Terry Eagleton (1991), ao afirmar que, em termos de cultura ocidental, não podemos pensar a crítica desvinculada do espaço público. Ela se constituiu na reconfiguração desse espaço público, a partir do advento da modernidade, associada à ascensão da esfera pública burguesa e liberal, ainda no século XVIII. Fundamental reafirmar a profunda ligação entre a crítica e a esfera pública, sua função seria abrir-se ao debate, convencer e convidar à contradição, assumindo posição no embate social de cada época em que exerce seu ofício. E hoje, se alguma função ainda queira ter, precisa urgentemente repensar a sua relação no atual constituição da esfera pública, imiscuir-se no debate e na luta presentes nesse contexto que vivemos, bastante diferente em relação aos tempos iniciais em que se configurou no ocidente.

Nesse longo trajeto percorrido pela crítica, diferentes posturas críticas foram sendo criadas, e o crítico foi ocupando distintas posições e funções; em alguns momentos muito relevantes e valorados socialmente, como o foram, por exemplo, no Brasil dos anos 50 e 60, e em outros, de quase completo apagamento, como, creio, nos tempos em que vivemos, o que acarreta, nesse caso, uma situação de crise e, concomitantemente, quero crer, de recriação. Mas para entender o processo que hoje vivemos, dentro da crítica musical massiva no Brasil, creio que seja necessário resgatar como se constitui historicamente os padrões de valoração críticos. Para isso, recorremos a uma análise mais teórica, em seguida voltamos no tempo e nos remontamos ao final dos anos 50 e à década de 60 , no Brasil.

\section{A construção da autoridade do crítico musical}

Como se dá o processo de formação da autoridade de um crítico musical? Para pensar sobre isso, podemos recorrer a Zelizer (1992) e sua análise sobre a formação da autoridade jornalística, como e porque se legitima, se reconhece ao jornalista a posição de autoridade cultural, aplicando tais reflexões para o caso específico do crítico de música.

Para Zelizer, essa autoridade é criada e age como fonte de conhecimento codificado que orienta as pessoas acerca de padrões adequados de ação. A partir da noção de representação coletiva de Durkheim, isto é, como se estruturam modos coletivos para a compreensão do mundo, a autora em questão sugere que tal autoridade é gerada "por pessoas que a ela dão sentido através de uma forma representativa". A criação dessa autoridade está também articulada com atos rituais que congregam membros de uma comunidade e que também são momentos adequados em que se torna possível questionar as autoridades até então existentes e se introduzir e consolidar novos membros no interior dessa comunidade. A autoridade cria uma comunidade em torno de seu campo de análise e atuação, estabelecendo, então, modos de atuação dentro dessa prática comunicativa, construindo-se, portanto, nesse jogo dialético, por um lado sendo resultado/constructo de uma comunidade e, por outro, atuando para manter essa comunidade articulada, congregada.

A reflexão de Zelizer nos remete a feita por Bourdieu (1986) e a sua noção de campo e de capital cultural e social. Para ser aceito e legitimado como crítico, o sujeito precisa possuir um conjunto de saberes gerais e específicos acumulados provenientes da família, de seus estudos sistemáticos acadêmicos e de sua 
vivência dentro no mundo da música, que Bourdieu chama de capital cultural incorporado, isto é, interiorização de disposições duradouras, que se estabelecem nos diferentes grupos por onde transitamos. Além de acumular bens culturais ligados ao campo musical (como livros, discos, dvds, cds, jornais, revistas ...) - capital cultural objetivado, isto é, transformado em bem cultural transmissível, materializado - e apropriar-se simbolicamente desses bens, tendo o instrumental necessário para acessá-los e decifrá-los. Porém, isso não é suficiente. Para ser legitimado como crítico musical precisa ser aceito pelo campo da crítica, estruturado com suas regras, sua autonomia relativa e suas relações de poder; espaço em que os diferentes agentes pertencentes ao campo se enfrentam em busca da legitimação. Para que isso ocorra, ainda de acordo com Bourdieu, o crítico precisa acumular um capital social conferido pelo grupo a partir das lutas, conflitos e relações estabelecidos no campo, o que possibilita seu reconhecimento e a ocupação de uma posição no mesmo. Sintetizando, em um campo estabelecido, os agentes e instituições estão em constante luta. Os que dominam o campo possuem os meios para fazê-lo funcionar em seu próprio benefício, mas cabe àqueles que desejam nele entrar e/ou transformá-lo resistir e, mais do que isso, estabelecer estratégias que o tornem aceito e legitimado. Seu investimento e sua estratégia visam acumular cada vez mais e o mais rápido possível esse capital social, pois sua legitimação interna e externa dependerá, em grande medida, desse processo. Importante lembrar também que a incorporação de novos membros, sobretudo daqueles que se contrapõem a preceitos já existentes ou que pretendem o alargamento do campo, acaba por redefinir o próprio campo.

Quanto ao trabalho crítico, nunca é demais dizer que é uma construção narrativa, feita por um sujeito que coloca em jogo uma leitura interpretativa a partir de pressupostos valorativos, sobre os quais baseia seu ofício. O crítico musical pode ocupar uma variedade de posições nesse processo de mediação entre criação, circulação e consumo da música no qual está inserido: porta-voz oficioso da indústria musical e dos artistas, massa de manobra usado para vender e difundir seus produtos, até mesmo incentivador e divulgador de projetos musicais aos quais se quer filiar; criar um discurso articulado com o mainstream ou afiliar-se ao underground; usar os espaços criados na grande mídia ou criar seus próprios espaços alternativos. Porém, quero crer que para exercer o papel de crítico de fato, precisa colocar o seu saber acumulado a serviço do desvelamento do senso comum que envolve o mundo da música.

O crítico ao mesmo tempo é fonte de informação e especialista em sua análise e interpretação, disposto interferir no debate e não a simplesmente descrever o que acontece. Mediação sempre foi e continua sendo um conceito-chave para entender o papel do crítico. No caso do crítico musical, ele seria aquele que faz múltiplas mediações: entre o criador e o público, aproximando a obra dos seus possíveis receptores e comunidades de gosto, decifrando os meandros da criação, os pressupostos que envolvem cantor-compositor, obra criada, situando no tempo e no espaço e, sobretudo, dentro do campo especificamente musical; entre criador e indústria fonográfica, sobretudo em casos de propostas alternativas e inovadoras, mostrando o seu potencial, podendo abrir ou cerrar espaços; entre criador e mídia, através de seu conhecimento acumulado, com seu instrumental de análise, apresentando e situando a criação em questão. O seu reconhecimento como crítico pelos seus iguais no campo da crítica e pelas demais esferas que envolvem a música massiva (criação, circulação e consumo) vai passar pela articulação que ele vai estabelecer nesses distintos momentos de mediação.

\section{Bossa Nova como parâmetro de valor}

No caso do Brasil, e mais especificamente dentro do campo da crítica da música massiva, como podemos pensar todo esse processo? A hipótese que aqui se defende é que, desde o final dos anos 50, a Bossa Nova (BN) foi colocada tanto por criadores quanto por críticos como o divisor de águas e parâmetro avaliativo principal para analisar o que veio antes e o que foi construído posteriormente. Essa hegemonia permaneceu ao longo do tempo e hoje, mesmo mantendo seus ferrenhos defensores, parece estar sendo questionada, ou pelo menos começam a surgir e ganhar força outros parâmetros que não aqueles bossa- 
novistas.

A ênfase narrativa é colocada no processo de modernização da música popular/massiva brasileira feito pela BN, cortando os excessos passionais, com apuro estético-formal, sedenta pela experimentação, exigindo um conhecimento musical mais apurado, dialogando com o popular e o massivo a partir do erudito. Podemos pensar na Bossa Nova como o momento em que os parâmetros do pensamento modernista, que adquiriu força no campo das artes no Brasil a partir da década de 20, são aplicados a música popular urbana (1).

De acordo com análise feita por Tárik de Souza, os criadores da BN trataram a música popular de maneira erudita, preocupando-se com harmonia, acordes e ritmos. Em termos técnicos, "o novo estilo permitia uma subversão completa dos conceitos antigos. Acordes alterados ou dissonantes, a nota fundamental fora do eixo do baixo; blocos de notas (cluster) de uma cor harmônica diferente; outras tonalidades, modulações e um acompanhamento rítmico que deixava de ser simétrico ou repetitivo para ganhar estrutura própria, independente do canto" (SOUZA, 1988: 206).

João Gilberto, além de inovar na interpretação - sem histrionismo, de forma intimista, à medida que os arranjos eram mais limpos, o cantor passou a usar a voz sem forçá-la, como se falasse -, inovou também no ritmo, criando uma nova batida de violão, acentuando o tempo fraco do ritmo e "sem os acordes de passagem que arredondavam o acompanhamento do samba e do choro" (Id.: 207).

É interessante ver como alguns críticos musicais analisavam os avanços trazidos pela $\mathrm{BN}$, é isso também nos dá os parâmetros analíticos que passam a ser hegemônicos. O crítico e estudioso Brasil Rocha Brito (apud CAMPOS, 1978: 17-40) sintetiza as inovações da BN em cinco grandes aspectos:

a) não reconhecimento da hegemonia de um determinado parâmetro musical sobre os demais, procurando assim integrar melodia, harmonia, ritmo e contraponto, sem destaque para nenhum deles;

b) superação do dualismo, do contraste entre cantor e orquestra, músicos e cantores integrados, evitando agudos gritantes, fermatas;

c) culto da música popular brasileira, buscando integrar, no universal da música, as peculiaridades específicas daquela.

d) respeito e valorização dos criadores do passado que, com "seriedade", produziram um trabalho de "alto nível elaborativo”, tais como Noel Rosa, Ismael Silva, Sinhô, Mário Reis;

e) valorização da pausa, do silêncio como agente de estruturação, aproximando a BN da música erudita de vanguarda.

Interessante perceber como se construiu essa hegemonia dos parâmetros da BN. Criou-se especialmente em torno de João Gilberto toda uma mitologia, alimentada pela imprensa, críticos e músicos, boa parte, proveniente de seu reconhecido talento musical, e é claro também da sua demonstrada excentricidade, sobretudo pelas suas rompantes em alguns shows e sua reclusão pública nos últimos anos. A narrativa criada em torno de João Gilberto o coloca como "gênio da espécie" em termos musicais, ao molde dos gênios românticos, acima do bem e do mal, em um mundo quase a parte, que quando dava seu ar da graça causava furor no séquito cada vez maior de seguidores, formados tanto por cantores-compositores, quanto pela crítica e estudiosos de música; mas, resgatando Williams, sem abarcar a totalidade. Cabe citar o caso de Tinhorão, um dos maiores estudiosos de música popular no Brasil, um exemplo dessa não unanimidade; ferrenho defensor da "pureza" de uma música com pretensas "raízes" brasileiras e 
combatente da $\mathrm{BN}$, pois a via como fruto da americanização de nossa música (2). Ele é exemplo do contraponto à crítica majoritária que se construiu em torno da $\mathrm{BN}$ e, sobretudo, de João Gilberto, defendendo uma cultura popular brasileira pretensamente "pura" e "original".

No entanto, o que é mais intrigante na construção da BN como parâmetro crítico maior da música feita no Brasil, e em João Gilberto como seu maior representante, são os discursos até hoje feitos por muitos críticos e cantores-compositores sobre o momento "mágico" quando, pela primeira vez, ouviram o mestre tocar e cantar. Vejamos alguns exemplos. Caetano Veloso, em Verdade Tropical (1997: 18), refere-se a João como "meu mestre supremo", e afirma: "A bossa nova nos arrebatou. O que eu acompanhei como uma sucessão de delícias para minha inteligência foi o desenvolvimento de um processo radical de mudança de estágio cultural que nos levou a rever o nosso gosto, o nosso acervo e [...] as nossas possibilidades. João Gilberto, com interpretação muito pessoal e muito penetrante do espírito do samba, [...] catalisou os elementos deflagradores de uma revolução" (VELOSO, 1997: 35-36).

Revolução essa que, ainda nos termos de Caetano, possibilitaram "o pleno desenvolvimento" dos demais companheiros geracionais, como Tom Jobim, Lyra ou Bôscoli, "deu sentido às buscas de músicos talentosos" do passado, como Dick Farney, Johnny Alf, "abriu um caminho para os mais novos que vinham chegando", como Nara leão, Menescal, Baden Pawell e ele próprio, apesar de não se auto-citar. Caetano conclui afirmando que a BN (João Gilberto em especial), "marcou, assim, uma posição em face da feitura e fruição de música popular no Brasil que sugeria programas para o futuro e punha o passado em nova perspectiva" abarcando os mais distintos setores: "músicos eruditos, poetas de vanguarda e mestres de bateria de escolas de samba" (Id.: 36).

De acordo com Edu Lobo (apud MELLO, 1976: 65), "a primeira grande revolução em termos das estruturas harmônicas, melódicas e, realmente, a primeira linguagem nova que se usou para fazer música no Brasil, foi a Bossa Nova." E continua, afirmando que "foi realmente a grande abertura para que a música brasileira pudesse enveredar por esse caminho moderno em que está hoje em dia". Já Chico Buarque é bastante enfático também, afirmando em entrevista (apud COSTA, 1969) que "eu sei que toco violão desde a época em que aprendi a ouvir João Gilberto. Esse foi meu passo inicial, não foi Noel nem qualquer dos outros que citei, foi o João, a música Jobim e a letra de Vinícius" Ou então Wisnick (1994: 3) ao afirmar que "nesse país soberano e singular, onde o popular e o erudito se entrelaçaram para sempre nas bachianas e na BN, a canção quer ser sinfonia, mas a sinfonia quer, mais ainda, ser canção." Ainda podemos citar Augusto de Campos (1978: 57), que em ensaio escrito em 1966, ao analisar a apresentação de João Gilberto no Carnegie Hall, em 62, afirma que ele "na sua vez, pediu simplesmente uma cadeira, sentou-se com seu violão, em meio a uma floresta de microfones, experimentou o som e mandou a sua música de sempre, sem alterar uma vírgula", e continua: "esse 'João de nada' fez tudo: ensinou voz e música ao mundo." Declarações semelhantes podem ser encontradas em Gal Costa, Gilberto Gil, Nara Leão, Toquinho, Marcos Valle, e tantos outros. São frases ditas à época e ainda repetidas no decorrer dos anos, afirmando uma narrativa em que se destacam expressões como "estupor", "não tinha ouvido nada igual antes", "fiquei paralisado", "genialidade", "tudo se desvelou para mim".

O mais intrigante, no entanto, é que essa narrativa também é repetida por alguns que sempre foram colocados pela crítica e músicos como tendo uma proposta antagônica, como é o caso dos criadores da Jovem Guarda: Roberto e Erasmo Carlos. O Tremendão afirmou em entrevista (apud LICHOTE, 2007: 1) que "sou filho do rock com a bossa nova". O caso de Roberto Carlos se apresenta ainda mais interessante. Aquele que veio a ser rotulado, nos anos 60, no Brasil, como o "Rei da Juventude", por conta do rock, ou simplesmente de "Rei", a partir dos 70, por conta da música romântica e dos sucessivos recordes de venda de discos, foi, no princípio da carreira "tomado" pela BN e João Gilberto. De acordo Paulo César de Araújo (2006), e também ao se ter acesso às primeiras gravações do Roberto, ele tentou lançar-se no mercado fonográfico repetindo, e para alguns, tentando copiar quase que literalmente João Gilberto, se 
não no toque de violão, no jeito de interpretar, imitando inclusive um certo acento baiano daquele (3). Ao ouvir "Chega de Saudade", com João Gilberto, na mesma linha que os depoimentos transcritos anteriormente, Roberto (apud ARAÚJO, 2006: 65) afirma que: "Nunca tinha ouvido nada parecido antes. A forma de ele cantar, a colocação da voz, a emissão, a afinação, a divisão, tudo ali era perfeito". E conclui: "Quando ouvi João Gilberto, eu fiquei parado, porque aquilo era algo simplesmente maravilhoso".

Os padrões estético-musicais estabelecidos por João Gilberto e pela BN passam a ser o signo maior do que seria considerado "fazer boa música", "música de qualidade" no Brasil. Mesmo críticos que buscam romper ou questionar os parâmetros de nossa crítica musical, acabam por reiterar o discurso, como é o caso mesmo de Araújo, que em um primeiro livro ("Eu não sou cachorro, não" - 2002) colocara em pauta uma releitura da chamada música brega, volta à carga em 2006 com sua já citada biografia sobre Roberto Carlos. A partir de uma exaustiva pesquisa, acaba por escrever um livro que, se por um lado, é bastante esclarecedor dos meandros de parte da história da indústria fonográfica brasileira, por outro, muitas vezes exagera no tom, assumindo um discurso grandiloquente, cheio de loas a seu ídolo maior, tentando forçar um diferencial entre a turma Bossa Nova, da zona sul carioca, liderada por Bôscoli, fenômeno para ele datado e circunstancial, e a bossa nova como "o estilo musical criado por João Gilberto", qualificado por ele como "atemporal" e "essência, o que é" (ARAÚJO, 2006: 75). Os primeiros, formando um clube fechado, que recusaram todas as tentativas de aproximação de Roberto Carlos e outros "intrusos" no ninho, o que poder ser exemplificado pela transcrição de frase de Erasmo Carlos: "Tenho quase certeza que eu e Roberto Carlos não somos hoje cantores de samba, de bossa nova, porque não conseguimos participar da turma deles" (Id.). Já João Gilberto é colocado acima do bem e do mal, e há uma clara tentativa de aproximar Roberto Carlos do mestre. Essa estratégia é bem exemplificada pela longa descrição feita no referido livro de uma possível ida do mestre para assistir a uma das apresentações que Roberto fazia na boate Plaza, onde cantava BN. Mais do que tentar afiliar Roberto à linhagem de João, afirma a primazia do Rei sobre os demais: "E João entrou para ver, ficando num cantinho lá atrás. E naquele momento ele se deparou no palco com o primeiro representante [grifo do autor] daquela geração dos anos 60 que surgiria se dizendo filho da sua arte", e conclui: "Sim, João Gilberto ouviu Roberto Carlos antes de conhecer Caetano Veloso, Chico Buarque, Gilberto Gil, Gal Costa, Edu Lobo, Marcos Valle e vários outros de seus fãs confessos". Reitera-se a genialidade do mestre, colocado como padrão de qualidade e dele se pede o aval: "Eu achei o Roberto muito musical" (ARAÚJO, 2006: 79).

Fica clara a tentativa de conectar-se com o legado da BN, aceito como padrão de qualidade, contrapondose a incorporação de tal legado pela geração posterior à BN, que veio a criar a Música Popular Brasileira, nos anos 60. Nomes como Chico Buarque, Edu Lobo, Elis Regina, Geraldo Vandré, Caetano Veloso, Gilberto Gil, Gal Costa, e vários outros estiveram na linha de frente.

Essa ênfase na qualidade intrinsecamente musical da BN, vista como inovadora, seminal, moderna e modernizadora da música popular no Brasil, parâmetro de análise para o que já foi feito, do que está e ainda vai ser feito torna-se dominante. Mesmo quando as circunstâncias se alteraram, há uma clara tentativa dessa geração pós-BN, antes citada, de permanecer conectada com os parâmetros dados pelos mestres, deles se apropriando como legítimos continuadores. Cabe analisar um pouco mais a fundo o caso da MPB e da Tropicália.

A partir de meados de 64 fortes mudanças aconteceram no cenário nacional, que acarretaram também mudanças na criação musical. O conteúdo semântico passou a ter uma importância fundamental diante da realidade de ditadura militar que o país passava a viver. A linguagem passou a abordar diretamente problemas sociais, da censura, ou, em tom de lamento, expondo as condições subumanas, sobretudo dos nordestinos e dos habitantes dos morros. A ênfase se colocava na arte engajada, articulada com o pensamento nacional-popular, preponderante nas esquerdas do período. Nos bares de DCEs, nos festivais 
da canção e em locais como o Solar da Fossa foi tomando forma o que se passou a chamar Música Popular Brasileira (4). Como bem analisa Wisnik (1996: 1), nesse período, a denominação Música Popular Brasileira vinha associada "a um purismo defensivo contra a cultura internacional [...] e contra o gosto e a presença das massas (o romantismo dito hoje brega, a música sertaneja, e outra vez a Jovem Guarda)"(5).

O pensamento hegemônico da crítica e dos criadores ligados à MPB exigia uma tomada de posição social, contra os arbítrios da ditadura militar implantada, passando a colocar ênfase no engajamento e em letras que retratassem essa realidade. A crítica do período passa a exigir do criador um posicionar-se no mundo, assumindo a defesa de valores não somente estéticos, mas explicitamente políticos, que deveriam ser incorporados na obra. Quem não produzisse nesses termos eram os "outros" a serem desqualificados, pois não faziam música brasileira, pelo menos não "de qualidade". Aí se encaixavam os casos de Roberto Carlos e, posteriormente, de Wilson Simonal, para somente citar dois casos conhecidos e emblemáticos. Mas e como encaixar-se João Gilberto e boa parte do legado da BN, feito em cima de letras exaltando "o amor, o sorriso e a flor"? Eles seriam revolucionários, musicalmente falando. A revolução musical e estética que propunham era o ponto de conexão que se resgatava. A brecha para se afirmarem como continuadores desse legado estava dada pela permanência da qualidade estética de suas composições, da qual se colocavam como herdeiros e continuadores.

No caso da Tropicália e sua relação com a BN, é interessante recorrer à análise feita por Luiz Tatit (2004). Para esse autor a BN foi fundamental para os rumos da canção popular no Brasil porque fez uma triagem de ordem estética, com seu gesto de eliminação dos excessos, "reduzindo o campo de inflexão vocal em proveito das formas temáticas, mais percussivas, de condição melódica" e dispensando "a intensidade e tudo que pudesse significar exorbitância das paixões" (Tatit, 2004: 49). A Tropicália, por sua vez, promoveu "a mistura e mundanização" da MPB, dando a entender "que a canção brasileira é formada por todas as dicções - nacionais ou estrangeiras, vulgares ou elitizadas, do passado ou do momento - e não suportaria qualquer gesto de exclusão" (Id.: 103). O gesto tropicalista foi incorporado à história da canção como um dispositivo de mistura a ser acionado toda vez que ocorresse a ameaça de exclusão; enquanto que o gesto da $\mathrm{BN}$, como um dispositivo de triagem, quando os excessos precisassem ser limados. Caetano Veloso e sua trupe tropicalista identificaram e incorporaram traços da cultura brasileira até então rejeitados ou recalcados pelos cultores de uma MPB "de qualidade" ou "genuína", transitando pelo rock internacional, pela Jovem Guarda, pela música chamada brega, pelo experimentalismo com a literatura, e solidificaram "esse ajuntamento com a imagem da 'geléia geral brasileira"" (Id.: 58).

Musicalmente os tropicalistas realizavam, no dizer de Wisnik (2001: 184) "a carnavalização paródica dos gêneros musicais, que se traduz[ia] numa densa trama de registros sonoros e poéticos", e para isso recorriam à estratégia antropofágica oswaldiana.

Além disso, cabe, no entanto, destacar o desejo de afiliar-se aos pressupostos da BN. Para Caetano (apud Veloso, Gullar et alii, 1966: 378) "a música brasileira se moderniza e continua brasileira", não devendo ficar atrelada a padrões fixos, pois "toda informação é aproveitada (e entendida) da vivência e da compreensão da realidade cultural brasileira". Não renegava a tradição, ao contrário, reafirmava-a: "Se temos uma tradição e queremos fazer algo de novo dentro dela, não só teremos de senti-la, mas conhecêla. E é este conhecimento que vai nos dar a possibilidade de criar algo novo e coerente com ela" (Id.).

A necessidade da "retomada da linha evolutiva" dentro da MPB, e que era a proposta da Tropicália, de acordo com Caetano, seria capaz de dar organicidade para "selecionar e ter um julgamento de criação", uma organicidade entendida como estruturação que possibilitasse "o trabalho em conjunto, interrelacionando as artes e os ramos intelectuais" (Id.). Antônio Cícero (2003: 208), analisando 
posteriormente essa fala de Caetano, afirma que quando ele se refere à linha evolutiva da MPB o que de fato está em questão é "manter viva a possibilidade, aberta pela BN" e "utilizar a informação da modernidade musical na recriação, na renovação, no dar-um-passo-à-frente da música popular brasileira" [grifo do autor] ou, em síntese, Caetano "estava simplesmente se opondo àqueles que combatiam qualquer inovação na música popular" (Id.). João Gilberto seria o parâmetro: "a informação da modernidade musical utilizada na recriação, na renovação, no dar um passo à frente da música popular brasileira" (Caetano, apud Veloso, Gullar et alii, 1966: 378), conjugando tradição e modernidade. Fica clara aqui a ênfase que tanto Caetano quanto Cícero querem dar à afiliação da Tropicália com a BN, sobretudo com seu mestre maior, João Gilberto.

\section{E hoje, como estamos?}

A partir do processo de globalização e das transformações dele decorrentes, do surgimento de novas tecnologias ligadas à comunicação, da enorme ampliação do contato entre culturas, em que a construção do conhecimento se vê fortemente marcada pela articulação das muitas e variadas informações a que estamos expostos, de um contexto marcado pela diversidade de propostas e possíveis alternativas, questionando-se os caminhos únicos e as verdades pré-estabelecidas, que estratégias a crítica musical precisa usar para responder a essas transformações?

Se os criadores passam a utilizar elementos provenientes dos avanços tecnológicos, ou por eles possibilitados, que facilitam a obtenção de novas sonoridades, a gravação e a circulação de seus trabalhos, e, sobretudo, se vemos surgir no horizonte um processo de criação não mais preso a regras e padrões únicos, mas sim à disposição para mesclar, hibridizar, traduzir propostas musicais aparentemente antagônicas, cabe ao crítico também se reconfigurar. Se os instrumentos de mediação se alteram e se ampliam, isso implica em alterar também seus critérios de análise, que precisam ser repensados, e também repensar seu papel no espaço público. É evidente que isso exige do crítico uma tomada de posição diante dos diversos agentes envolvidos; enfrentamentos, diálogos e articulações são levados a cabo no desempenho de seu ofício de crítico. Sua aceitação e prestígio estarão sempre em jogo nesse processo. Sua produção crítica precisa ir além das pressões cotidianas e das necessidades jornalísticas de apresentar os espetáculos, os lançamentos de álbuns, entrevistar os artistas, enfim de se ater à mera descrição dos acontecimentos musicais; o que dele se exige é mergulhar numa reflexão analítica para desvendar os entremeios, o não dito do discurso proferido. Fugir do lugar comum e decifrar o processo, problematizar e levantar questões.

No exíguo espaço que o crítico musical tem ocupado nos grandes jornais e revistas impressos hoje, o que se tem observado é que muitos se transformaram em simples "guias de consumo", indicando o que se deve ou não comprar, reproduzindo releases já previamente prontos, participando e reproduzindo entrevistas coletivas previamente agendadas. Como nos lembra Sérgio Miceli (apud SOARES, 2007), o modelo clássico de crítica cultural opinativa nos jornais parece superado, restando ao crítico de imprensa o papel de "reagir pontualmente, num espaço superdiminuto, a uma agência também complicada". Talvez seja essa uma das razões pelas quais vemos crescer espaços alternativos para a crítica musical, explorando as muitas possibilidades trazidas pelos avanços tecnológicos e comunicacionais, sejam em blogs, sites especializados ou revistas eletrônicas; portanto, não mais se atendo ao espaço cada vez mais reduzido do jornal. Tal estratégia parece levar em conta a necessidade de maior liberdade para o aprofundamento analítico, fomentando a criação de redes de pessoas interessadas no campo da crítica musical, abrindo-se a novas propostas e dialogando com esses novos sujeitos da criação musical, não mais se atendo aos velhos padrões da crítica (6).

Afinal não parece suficiente reduzir-se a "guia de consumo"; é papel do crítico colocar-se a serviço de uma prática teórica e prática de auxiliar a desvendar os meandros da criação, circulação e consumo da 
produção musical, situando-a no tempo e no espaço mais geral da contemporaneidade e no mais específico do campo propriamente musical. Para além de uma análise que se atenha a descrever o que está dado como algo consumado e a ser consumido, desvendar os entroncamentos dos discursos criados, tanto pela indústria fonográfica e seus executivos, quanto pelos criadores e seu público, assumindo sua posição e fomentando o debate.

\section{Bibliografia:}

ARAÚJO, P. C. Roberto Carlos em detalhes. São Paulo: Planeta do Brasil, 2006.

BOURDIEU, P. A Distinção: crítica social do julgamento. São Paulo: Edusp; Porto Alegre: Zouk, 2008.

. "The Forms of Capital". In: Richardson, J. G. (ed.). Handbook of Theory and Research for the Sociology of Education. Greenwood Press, New York: 1986, pp.241-258.

BRITO, B.R. "Bossa Nova”. In: CAMPOS, A. Balanço da bossa e outras bossas. São Paulo: Perspectiva, 1974, pp.17-40.

CAMPBELL, R. 60 minutes and the news: a mythology for Middle America. Urbana \& Chicago: Univiversity of Illinois Press, 1991.

CAMPOS, A. Balanço da bossa e outras bossas. São Paulo: Perspectiva, 1974.

CÍCERO, A. "O tropicalismo e a MPB”. In: DUARTE, P. S. \& CAMBRAIA NAVES, S. (org.). Do Samba-canção à Tropicália. Rio de Janeiro: Relume Dumará, 2003, pp.201-214.

COSTA, Flávio M. "Encontro com Chico”. O Jornal, Rio de Janeiro, 17/06/1969.

EAGLETON, T. A função da crítica. São Paulo: Martins Fontes, 1991.

HOMEM DE MELLO. Música popular brasileira. São Paulo: Melhoramentos, 1976.

LICHOTE, L. "Nome: Erasmo Carlos. Pai: Rock. Mãe: Bossa Nova”. O Globo, Segundo Caderno, 06/05/2007, p.1.

NERCOLINI, Marildo J. Artista-intelectual: a voz possível em uma sociedade que foi calada. Porto Alegre: UFRGS, 1997 (dissertação de mestrado).

- A construção cultural pelas metáforas: A MPB e o Rock Nacional Argentino repensam as fronteiras globalizadas. Rio de Janeiro: UFRJ, 2005 (tese de doutorado).

NERCOLINI, Marildo J. \& WALTENBERG, Lucas. "Novos mediadores na crítica musical". In: PEREIRA DE SÁ, Simone (org.). Rumos da cultura da música. Porto Alegre: Sulina, 2010.

SOARES, C. C. “A crítica cultural hoje, segundo Sérgio Miceli e Marcelo Coelho". Revista Trópico. In: http://pphp.uol.com.br/tropico/html/textos/1694,1.shl. Acesso em: 07/05/2007.

SOUZA, T. "A bossa nova e o fino da bossa”. In: SOUZA, T. et alli. Brasil musical. Rio de Janeiro: Art 
Bureau, 1988, pp.199-217.

TATIT, L. O século da canção. Cotia: Ateliê Editorial, 2004.

TINHORÃO, J. R. Música popular: um tema em debate. Rio de Janeiro: JCM [1969].

WILLIAMS, R. Marxismo e literatura. Rio de Janeiro: Zahar, 1979.

. Cultura. Rio de Janeiro: Paz e Terra, 2000.

VELOSO, C. Verdade tropical. São Paulo: Companhia das Letras, 1997.

\section{Notas:}

Artigo apresentado no Grupo de Trabalho Cultura das Mídias no XIX Encontro da Compós, PUC-RJ, em junho de 2010, a quem agradeço as contribuições no debate.

(1) Agradeço a reflexão feita por Renato Cordeiro Gomes sobre essa questão.

(2) Ver TINHORÃO, 1969.

(3) Ver http://robertocarlos.globo.com/html/home/home.php?pagina=8, em que constam as gravações feitas por RC.

(4) Ver NERCOLINI, 1997.

(5) Ver NERCOLINI, 2005.

(6) Sobre esse processo de reconfiguração da crítica, ver NERCOLINI \& WALTENBERG (2010).

\section{Mini Currículo :}

Professor do Departamento de Estudos Culturais e do Programa de Pós-Graduação da Universidade Federal Fluminense (UFF). 